\section{Bovine Aortic Endothelial Cells Elaborate an Inhibitor of the Generation of Lipopolysaccharide-stimulated Human Blood Monocyte Procoagulant Activity}

\author{
Lawrence Tim Goodnough, Mary Ellen Kleinhenz, \\ George H. Goldsmith, Jr., Nicholas P. Ziats, \\ and Abel L. Robertson, Jr. \\ Departments of Medicine and Pathology, Case Western Reserve \\ University, School of Medicine, Cleveland, Ohio 44106
}

A eration of procoagulant activity by human blood monocytes. Confluent endothelial monolayers were cultured for up to $96 \mathrm{~h}$. At timed intervals, culture supernatants were collected and incubated for $5 \mathrm{~h}$ with lipopolysaccharide-stimulated human peripheral blood mononuclear cells. The procoagulant activity of mononuclear cell lysates was determined in a one-stage clotting assay. In five experiments, procoagulant activity with culture supernatant (time 0 ) was $2,294 \pm 761 \mathrm{U} / \mathrm{ml}$ (mean \pm SEM). Culture supernatants from endothelial cells incubated for 24-96 h strongly inhibited mononuclear cell generation of procoagulant activity. Indomethacin $(10 \mu \mathrm{M})$ added to endothelial cells delayed the appearance of procoagulant inhibitor for $72 \mathrm{~h}$. Bovine aortic smooth muscle cell culture supernatants did not inhibit procoagulant activity. The inhibitor was heat stable, effective at 1:50 dilution, soluble, and acid sensitive, with a molecular weight of $<1,500$. Further studies on subpopulations of mononuclear cells demonstrated that endothelial inhibitor selectively decreased the generation of monocyte procoagulant activity and interfered with $\mathrm{T}$ lymphocyte amplification of monocyte production of procoagulant activity. Thus, we have demonstrated that endothelial cells elaborate a potent inhibitor of monocyte procoagulant activity.

Dr. Goodnough is the recipient of a Clinician-Scientist Award (81-412) from the American Heart Association.

Received for publication 2 August 1982 and in revised form 12 March 1984.

J. Clin. Invest.

(c) The American Society for Clinical Investigation, Inc.

0021-9738/84/07/0075/07 \$1.00

Volume 74, July 1984, 75-81

\section{Introduction}

Vascular endothelial cells have important interactions with components of blood coagulation. They synthesize prostacyclin, which inhibits platelet aggregation (1). They also synthesize and secrete a plasminogen activator $(\mathrm{PA})^{1}(2)$ which may contribute to the dissolution of fibrin clots in the vascular lumen. Endothelial cells are thought to be the primary source of the high molecular weight subcomponent of human antihemophilic factor (Factor VIII-related antigen) (3) and have been shown to have some thromboplastic activity (4). They also have receptors for thrombin (5) that may play a role in the activation of protein C (6).

Increasing evidence suggests that peripheral blood monocytes (PBMs) also may be important in blood coagulation. PBMs synthesize PA (7). They have been shown to have receptors for thrombin binding (8); as precursors of the reticuloendothelial system they may thus have an important role in clearing activated components of the coagulation cascade. In addition, PBMs generate procoagulant activity (PCA), identified as tissue factor, and can activate, in vitro, the extrinsic blood coagulation pathway (9).

More recently, investigators have shown that PBMs have important interactions with vascular endothelial cells. PBMs secrete a monocyte growth factor that affects human vascular cell proliferation (10). Fc-dependent binding of PBMs occurs in areas of endothelial injury (11). These observations link circulating PBMs with the injury-repair cycle believed to be important in atherogenesis $(12,13)$.

In this report, we present evidence that bovine aortic endothelial cells (BAEs) elaborate an inhibitor of the generation of human blood monocyte PCA.

1. Abbreviations used in this paper: BAE, bovine aortic endothelial cell; $\mathrm{Cm}$, conditioned culture medium; DMEM, Dulbecco's modified Eagle's medium; FBS, fetal bovine serum; LPS, lipopolysaccharide; PBM, peripheral blood monocyte; PBMC, peripheral blood mononuclear cell; PA, plasminogen activator; PCA, procoagulant activity; SMC, smooth muscle cell. 


\section{Methods}

\section{Cell cultures}

$B A E s$. Endothelial cells from adult bovine aortae were isolated according to previously described methods with minor modifications $(14,15)$. Thoracic aortic segments, 15 to $20 \mathrm{~cm}$ long, were dissected free of adventitial fat, intercostal branches were ligated, and one end was tied off with umbilical tape. The aortae were rinsed three times with Dulbecco's phosphate buffered saline (PBS) to remove blood and were refilled with a solution of collagenase $(1 \mathrm{mg} / \mathrm{ml}$; type I; Worthington Biochemical Corp., Freehold, NJ) in Hanks' balanced salt solution. The upper ends of the vessels were tied off and incubated at $37^{\circ} \mathrm{C}$ for $15-20 \mathrm{~min}$. After incubation, the collagenase solution was saved and each vessel was refilled and rinsed three times with Dulbecco's modified Eagle's medium (DMEM; Gibco Laboratories, Grand Island, NY) supplemented with $20 \%$ heat-inactivated $\left(56^{\circ} \mathrm{C}, 30 \mathrm{~min}\right)$ fetal bovine serum (FBS; KC Biological, Lenexa, KS).

Cells from the collagenase digest and washings were pooled, centrifuged, and resuspended in fresh DMEM with $20 \% \mathrm{FBS}$, and plated into T-75 flasks (Costar Corp., Cambridge, MA). In these experiments, confluent BAEs were subcultured from the flasks into $35-\mathrm{mm}$ petri dishes (Corning Glass Works, Corning, NY) by brief trypsinization (1 $\mathrm{mg} / \mathrm{ml}$ trypsin) (type TRL; Worthington Biochemical Corp.). Cells were seeded at a density of $2 \times 10^{5}$ cells per dish in $2 \mathrm{ml}$ of DMEM with $20 \%$ FBS. After $24 \mathrm{~h}$, cell cultures were refed with fresh medium. After an additional $72 \mathrm{~h}$ to allow cells to reach confluence, the media from confluent cultures were removed and the monolayers were rinsed with Dulbecco's PBS. At time 0, $2 \mathrm{ml}$ of DMEM with $10 \%$ FBS was added to each dish with or without the indicated concentration of indomethacin (Sigma Chemical Co., St. Louis, MO). At timed intervals thereafter, conditioned culture medium $(\mathrm{Cm})$ from individual dishes was aspirated and stored in duplicate at $-70^{\circ} \mathrm{C}$ for later testing. The corresponding cell culture monolayers were counted on a cell counter (Coulter Electronics, Inc., Hialeah, FL). BAEs underwent 5-12 serial passages during our experiments. Cells were $>99 \%$ viable as tested by the trypan blue dye exclusion test and were also positive for antihemophilic factorrelated antigen (15). The morphologic appearance of confluent vascular endothelial cells used in these experiments is seen in Figure $1 A$.

Bovine aortic smooth muscle cells (SMCs). SMCs were obtained by use of the same aortic segments from which endothelial cells were derived, as described above. Briefly, after collagenase treatment to remove endothelium, segments of intima and media were removed by dissection and minced into $\sim 1-\mathrm{mm}$ squares. The explants were implanted between two coverslips (envelope technique) as previously described (16). The coverslips were placed into Leighton tubes and each tube was filled with $1.5 \mathrm{ml}$ of DMEM plus 10\% FBS and refed every 3-4 d. When solid outgrowth around the explants was obtained (usually 2-3 wk), the coverslips were separated, the explants were removed, and the cells were removed by trypsinization. SMCs were routinely cultured in DMEM plus 10\% FBS in T-75 flasks.

In these experiments, SMCs were used for between 2-8 passages. Cells were subcultured into 35-mm dishes with DMEM plus 10\% FBS. The experimental conditions for SMCs were the same as described above for BAEs. The morphology of confluent bovine vascular SMCs used in these experiments is seen in Figure $1 B$.

Peripheral blood mononuclear cell (PBMC) separation and culture. PBMCs were separated from heparinized human peripheral blood by Ficoll-Hypaque sedimentation (17). T cells ( $>99 \%$ sheep rosetting cells, $<1 \%$ peroxidase staining) were prepared by sequential incubation of PBMCs in plastic petri dishes and nylon wool columns (8). A monocyte-
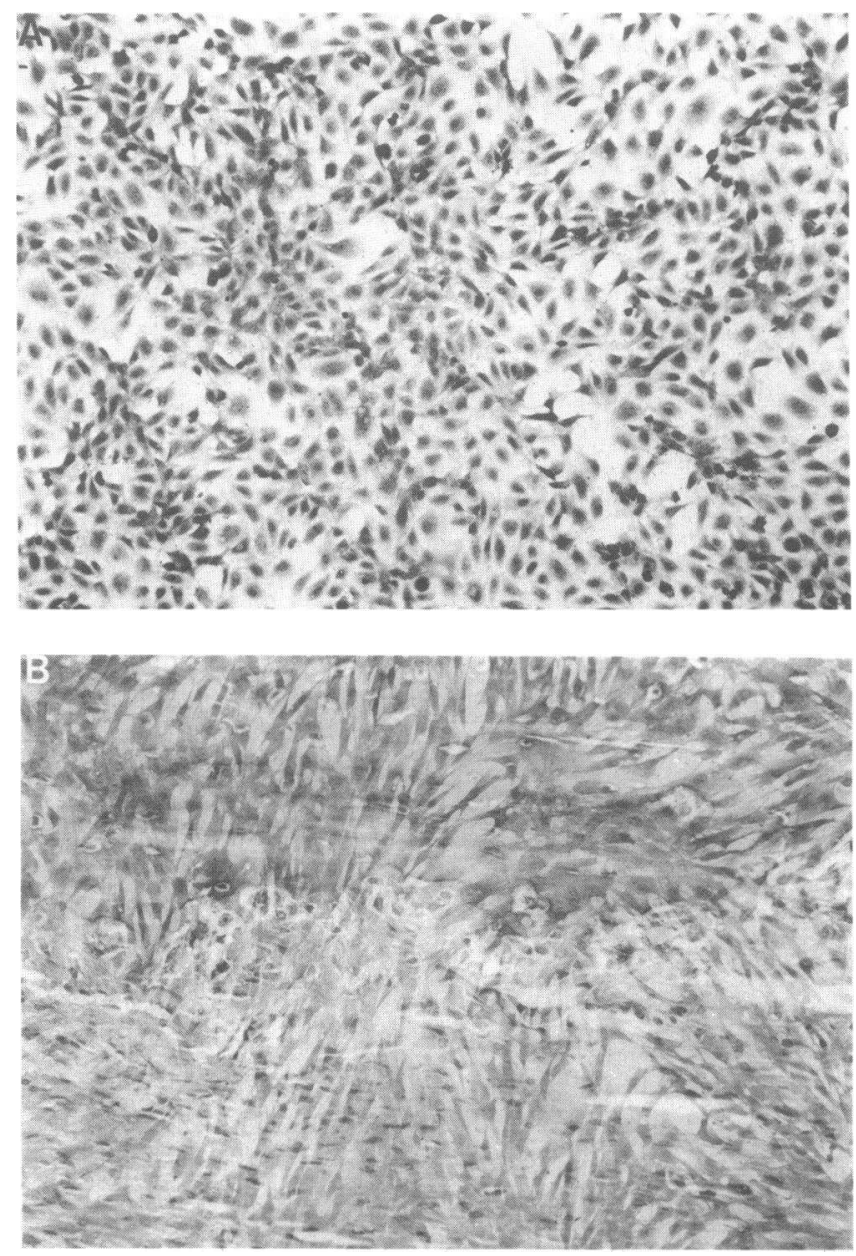

Figure 1. (A) Confluent BAEs. Low-powered (110X, total magnification) micrograph of cells cultured until confluent (72 h), fixed in $10 \%$ formalin, and stained with May Gründwald-Giemsa. $(B)$ Confluent bovine aortic SMCs that were processed in a similar manner as in $A$.

enriched cell fraction, $>\mathbf{9 0 \%}$ peroxidase staining) was recovered from the plastic dishes by gentle scraping with a rubber policeman. Mononuclear cells were suspended in RPMI-1640 (M.A. Bioproducts, Walkersville, MD) supplemented with $50 \mathrm{U} / \mathrm{ml}$ penicillin, $5 \mu \mathrm{g} / \mathrm{ml}$ gentamicin, and $2 \mathrm{mM}$ L-glutamine. Cells were cultured at $2 \times 10^{6} / \mathrm{ml}$ in $\mathrm{Cm}$ or DMEM plus $10 \% \mathrm{FBS}$ for $5 \mathrm{~h}$ at $37^{\circ} \mathrm{C}$ in $5 \% \mathrm{CO}_{2}$, then frozen at $-70^{\circ} \mathrm{C}$. PCA was stimulated with lipopolysaccharide (LPS) (E. coli 0127:B8; Difco Laboratories Inc., Detroit, MI), $10 \mu \mathrm{g} / \mathrm{ml} .10 \mu \mathrm{M}$ indomethacin was added to some cultures.

PCA assay. PCA of PBMCs was determined in a one-stage clotting assay $(18,19)$. PBMCs were disrupted by repeated (three times) freezethaw cycles. Equal volumes $(0.1 \mathrm{ml})$ of cell lysate, prewarmed pooled human plasma, and $0.025 \mathrm{M} \mathrm{CaCl}_{2}$ were then mixed and the clotting time was recorded. PCA units were calibrated from rabbit brain throm-

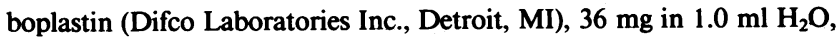
arbitrarily assigned a value of $100,000 \mathrm{U} / \mathrm{ml}$ (19); a double logarithm plot of clotting time versus thromboplastin concentration generated a straight line to a $10^{5}$ dilution of the standard. Serial dilutions of PBMC suspensions generated a line whose slope was identical to that of the 
standard curve. The assay was Factor VII-dependent (loss of 95\% activity when Factor VII-deficient plasma was substituted for pooled human plasma) and diisophosphofluorate resistant. Activity was expressed as the mean of duplicate values.

PA assay. PA of confluent monolayers of BAEs was assayed by a modification of a previously described amidolytic technique (20). After removal of $\mathrm{Cm}$, monolayers adherent to $35-\mathrm{mm}$ petri dishes were washed three times with phosphate-buffered saline, detached, and extracted with $0.1 \%$ Triton X-100 in $\mathrm{H}_{2} \mathrm{O}$, and the extract $(0.5 \mathrm{ml})$ was frozen at $-70^{\circ} \mathrm{C}$ until assay. All assays in an experiment were performed on either fresh or once-thawed samples. Plasminogen dependence of the enzymatic activity was assured by concomitant assay of identical sample aliquots in the absence of plasminogen, which uniformly generated no plasminlike amidolytic activity. Samples were assayed either undiluted or at a dilution demonstrating plasmin activity, which could be plotted on a linear curve obtained with serial dilutions of urokinase (CalbiochemBehring Corp., American Hoechst Corp., San Diego, CA) in the same assay system. Results are recorded in PA units (arbitrary units relative to urokinase) $/ 2 \times 10^{5}$ cells.

Column chromatography. Sephadex G15 (Pharmacia Fine Chemicals Inc., Piscataway, NJ) was swollen in RPMI (Gibco Laboratories) containing $50 \mathrm{U} / \mathrm{ml}$ penicillin and $50 \mu \mathrm{g} / \mathrm{ml}$ streptomycin (Gibco Laboratories). The gel was packed in a $1.5 \mathrm{~cm} \times 50 \mathrm{~cm}$ column and run at $30 \mathrm{~cm}$ pressure. $30 \mathrm{ml}$ RPMI containing $2 \mathrm{mg} / \mathrm{ml}$ blue dextran and 1 $\mathrm{M} \mathrm{NaCl}$ was used to calibrate the column. $2.5 \mathrm{ml}$ BAE culture media (96 h) was applied to the column, which was then eluted with RPMI in 1.8-ml eluate fractions.

Statistics. Data were analyzed by the $t$ test for tests of significant differences unless otherwise stated. Data for Fig. 3 were subjected to analysis of variance and covariance with repeated measures (BMDP2V, University of California, Los Angeles) with one grouping factor (cell group) and one within factor (culture time). Data in Table $\mathrm{V}$ were analyzed using the paired $t$ test.

\section{Results}

In five experiments, cultured BAEs elaborated an inhibitor of human PBMC procoagulant activity (Fig. 2). PBMC had a base-

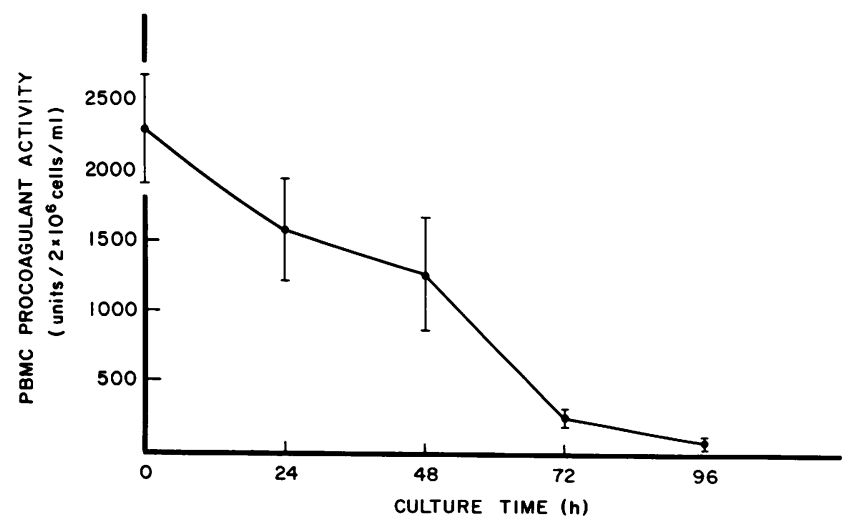

Figure 2. Effect of BAE culture medium on PBMC procoagulant activity. Aliquots of medium from BAE incubated for various time intervals (abscissa) were cocultured with LPS-stimulated PBMCs (solid line). The generation of PCA by PBMCs was determined in a onestage clotting assay and converted to units per milliliter from a standard curve using rabbit brain thromboplastin (ordinate).

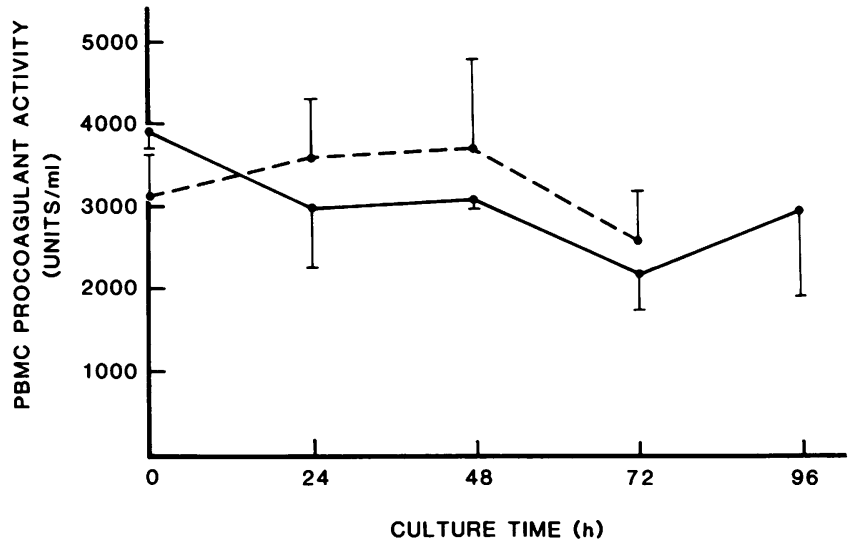

Figure 3. Culture supernatants from bovine aortic SMCs (solid line) and control cultures without cells (broken lines) do not inhibit PBMC procoagulant activity ( 0.4823 by analysis of variance). Methods as in Fig. 2. Bars indicate SEM.

line PCA of $2,294 \pm 761 \mathrm{U} / 2 \times 10^{6}$ cells per ml (mean \pm SEM) when cocultured with $\mathrm{Cm}$ that had been briefly exposed to freshly washed BAEs (time 0 ). $\mathrm{Cm}$ that had been incubated for up to $96 \mathrm{~h}$ progressively inhibited the generation of PCA during coculture with PBMCs (Fig. 2). Simultaneous cell counts of cultured BAEs showed only a slowly increasing number of viable cells throughout the incubation period $\left(1.4 \times 10^{6} / \mathrm{dish}\right.$ at time 0 to $2.6 \times 10^{6} /$ dish at $96 \mathrm{~h}$ ). Control experiments showed that $\mathrm{Cm}$ added to PBMCs after a 5-h incubation in the presence of LPS $(10 \mu \mathrm{g} / \mathrm{ml})$ did not block the expression of PCA in our clotting assay. Similarly, $\mathrm{Cm}$ did not block the expression of PCA by rabbit brain thromboplastin.

Parallel experiments demonstrated that bovine SMC culture supernatants did not inhibit PBMC procoagulant activity generation, nor did culture supernatants from control wells without cells that were incubated at $37^{\circ} \mathrm{C}$ and $5 \% \mathrm{CO}_{2}$ (Fig. 3).

Serial dilution of $\mathrm{Cm}(96 \mathrm{~h})$ with DMEM plus $10 \%$ FBS before coculture with PBMCs resulted in increasing generation of PCA. Dilutions of $\mathrm{Cm}$ as much as 1:50 generated a line whose slope paralleled the line obtained by serial dilutions of rabbit brain thromboplastin (Fig. 4), demonstrating the potency of the inhibitor and excluding the possibility that BAEs simply depleted $\mathrm{Cm}$ of critical nutrients required for the generation of PCA.

The effects of freeze-thawing, storage at $-70^{\circ} \mathrm{C}$, incubation at increasing temperatures, and acidification-neutralization were investigated (Table I). The inhibitor was stable to freeze-thawing and short-term storage at $-70^{\circ} \mathrm{C}$ but lost $\sim 25 \%$ activity upon storage for up to $120 \mathrm{~d}$ or incubation at various temperatures. Complete loss of inhibitory activity was seen with acidificationneutralization.

To determine if the inhibitor was soluble or membraneassociated, BAE culture medium $(72 \mathrm{~h})$ was separated into supernatant and precipitate by ultracentrifugation at $150,000 \mathrm{~g}$ for $30 \mathrm{~min}$ at $4^{\circ} \mathrm{C}$. Each fraction was then co-incubated with PBMCs in the presence of LPS, $10 \mu \mathrm{g} / \mathrm{ml}$, for $6 \mathrm{~h}$, and the 
RABBIT BRAIN THROMBOPLASTIN (U/ml)

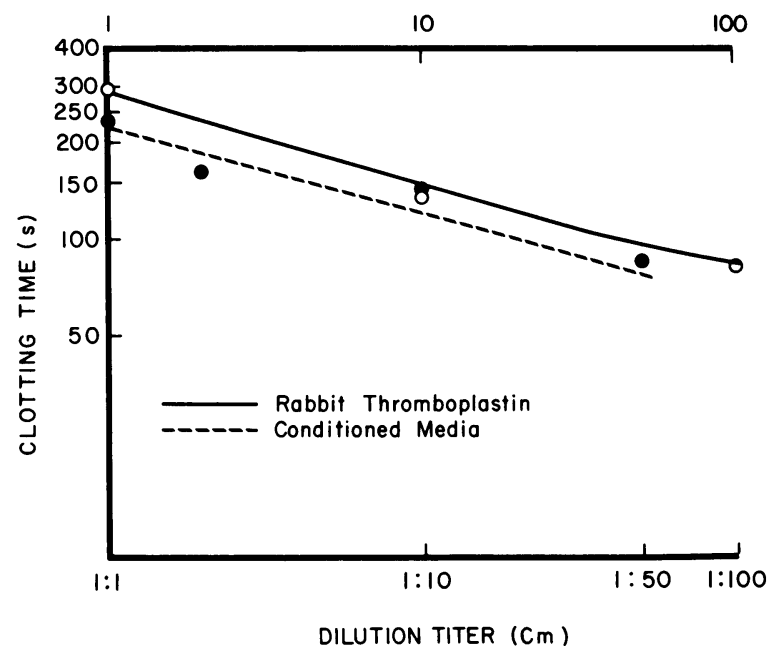

Figure 4. Effect of $\mathrm{Cm}$ dilution on PBMC procoagulant activity. Serial dilutions of BAE $\mathrm{Cm}$ containing inhibitor (broken line, closed circles) with increasing amounts of rabbit brain thromboplastin used as a standard (solid line, open circles) progressively shorten the clotting time in a PBMC procoagulant assay.

generation of PBMC procoagulant activity was assayed (Table II). Inhibition of PCA generation by PBMC was demonstrated by unspun and supernatant BAE culture media; no inhibition was demonstrated in precipitates of BAE culture media, indicating that BAE procoagulant inhibitor is soluble and not membrane associated.

Whereas PCA of blood mononuclear cells has been identified as the product of circulating monocytes, recent experimental evidence demonstrates that in vitro monocyte PCA generation

Table I. Stability of BAE Inhibitor to

PBMC Procoagulant Activity

\begin{tabular}{lr}
\hline & PCA \\
\hline & $U / m l$ \\
No inhibitor & 2,100 \\
Inhibitor & \\
$-70^{\circ} \mathrm{C}, 5 \mathrm{~d}$ & 50 \\
$-70^{\circ} \mathrm{C}, 30 \mathrm{~d}$ & 485 \\
$-70^{\circ} \mathrm{C}, 120 \mathrm{~d}$ & 540 \\
$4^{\circ} \mathrm{C}, 18 \mathrm{~h}$ & 500 \\
$37^{\circ} \mathrm{C}, 18 \mathrm{~h}$ & 570 \\
$56^{\circ} \mathrm{C}, 30 \mathrm{~min}$ & 640 \\
Acidification-neutralization & \\
\hline
\end{tabular}

* $\mathrm{Cm}(72 \mathrm{~h})$ titrated with $2 \mathrm{~N} \mathrm{HCL}$ to $\mathrm{pH} 2.6$ for $90 \mathrm{~min}$ at $20^{\circ} \mathrm{C}$, then titrated with $4 \mathrm{~N} \mathrm{NaOH}$ to $\mathrm{pH} 7.5$ and frozen at $-70^{\circ} \mathrm{C}$.
Table II. Evidence that BAE Procoagulant Inhibitor Is Soluble and Not Membrane Associated

\begin{tabular}{lc}
\hline & PCA $^{*}$ \\
\hline & $U / m l$ \\
PBMC & \\
+ LPS & $2,325 \pm 425$ \\
+ BAE culture media $(72$ h), unspun $\ddagger$ & $860 \pm 119$ \\
+ BAE culture media, supernatant $\ddagger$ & $810 \pm 51$ \\
+ BAE culture media, precipitate & $5,400 \pm 469$
\end{tabular}

* Human mononuclear cells incubated with $10 \mu \mathrm{g} / \mathrm{ml} \mathrm{LPS}$ at $37^{\circ} \mathrm{C}$, $5 \% \mathrm{CO}_{2}$, for $6 \mathrm{~h}$ and assayed for the generation of cell PCA. ¥ BAE culture media separated into supernatant and precipitate by ultracentrifugation at $150,000 \mathrm{~g}$ for $30 \mathrm{~min}$ at $4^{\circ} \mathrm{C}$ co-incubated with human mononuclear cells in the presence of LPS, $10 \mu \mathrm{g} / \mathrm{ml}$, for $6 \mathrm{~h}$ and assayed for the generation of mononuclear cell PCA.

in response to LPS, immune complexes, or very low density lipoprotein is augmented by collaborative interaction with $\mathrm{T}$ lymphocytes present in cell cultures (19). Thus, the decreased PCA generated by LPS-stimulated PBMC cultured in BAE culture media could reflect a direct inhibition of monocyte synthetic function or result from decreased $\mathrm{T}$ cell amplification. To distinguish between these possibilities, purified PBM and T lymphocyte fractions were prepared, and the effects of $\mathrm{Cm}$ on PCA generation and $\mathrm{T}$ lymphocyte collaboration were examined (Table III). In these studies, Cm decreased by $60 \%$ the LPS-stimulated PCA of PBMs cultured alone and by $71 \%$ the PCA of PBMs cultured with T lymphocytes. When PBMs were incubated with $\mathrm{Cm}$ for $2 \mathrm{~h}$, washed, and added to T lymphocytes, the

Table III. Inhibition of Monocyte Procoagulant Generation: Results of Cell Mixing Experiments

\begin{tabular}{lllrr}
\hline $\begin{array}{l}\text { Cells } \\
\text { in culture* }\end{array}$ & Preculture conditions $\ddagger$ & $\begin{array}{l}\text { Addition } \\
\text { to cell culture }\end{array}$ & PCA & Inhibition \\
\hline & & & & $\%$ \\
MN & - & LPS & 2,333 & \\
MN & - & Cm + LPS & 930 & 60 \\
T + MN & - & LPS & 3,389 & \\
T + MN & - & Cm + LPS & 978 & 71 \\
T + MN & T with Cm & LPS & 2,800 & 18 \\
T + MN & T with Cm and LPS & - & 3,889 & 0 \\
T + MN & MN with Cm & LPS & 1,622 & 48 \\
& & & & \\
\hline
\end{tabular}

* In cell mixing experiments, $\mathrm{T}$ lymphocytes $(\mathrm{T})$ and monocytes $(\mathrm{MN})$ are combined at a $\mathrm{T} / \mathrm{MN}$ ratio $=3: 1$ to achieve a final cell density of $2 \times 10^{6} / \mathrm{ml}$. $¥ \mathrm{~T}$ or $\mathrm{MN}$ were incubated with $\mathrm{Cm}$ or $\mathrm{Cm}$ $+\mathrm{LPS}, 10 \mu \mathrm{m} / \mathrm{ml}$, for $2 \mathrm{~h}$, then washed, resuspended, and added to the reciprocal cell fraction. $\S P C A$ is the mean of duplicate values, expressed as units $/ 10^{6}$ monocytes. 
LPS-stimulated PCA was $52 \%$ that observed in identical cell mixtures without $\mathrm{Cm}$ exposure. Thus, $\mathrm{Cm}$ interfered with monocyte generation of PCA. In addition, there was an $18 \%$ decrease in LPS-stimulated PCA when T lymphocytes were incubated with $\mathrm{Cm}$ and washed before the addition of PBM and LPS. This effect was not observed when $T$ lymphocytes were pre-incubated with both $\mathrm{Cm}$ and LPS, indicating that $\mathrm{Cm}$ inhibition of $\mathrm{T}$ cell collaboration was not a physical interference with LPS processing by $\mathrm{T}$ lymphocytes. Taken together these data demonstrate a direct inhibition of monocyte PCA generation by $\mathrm{Cm}$ and an effect of $\mathrm{Cm}$ on $\mathrm{T}$ lymphocyte amplification of PCA generation.

To determine the approximate molecular weight of BAE inhibitor, BAE culture media was subjected to Sephadex G-15 chromatography (Fig. 5). Elution fractions were cocultured with PBMCs (see Methods), and the effect on the generation of PCA by PBMC was assayed. Inhibition of PBMC procoagulant activity was detected in the elution fraction just before the elution of $\mathrm{NaCl}$, confirming that the inhibitor is of very low molecular weight.

BAEs are known to produce and secrete PA $(2,20)$. It has been previously demonstrated that the introduction of fresh serum-containing media on confluent endothelial cells suppresses the secretion of plasminogen activator (21). PA secretion by BAE recovers 72-96 $\mathrm{h}$ after exposure to fresh serum-containing media. Therefore, assays for BAE procoagulant inhibitor and PA were performed to see if their elaboration occurred in parallel in BAE cultures that had been washed and refed with DMEM plus $10 \%$ FBS. At timed intervals, culture media were removed

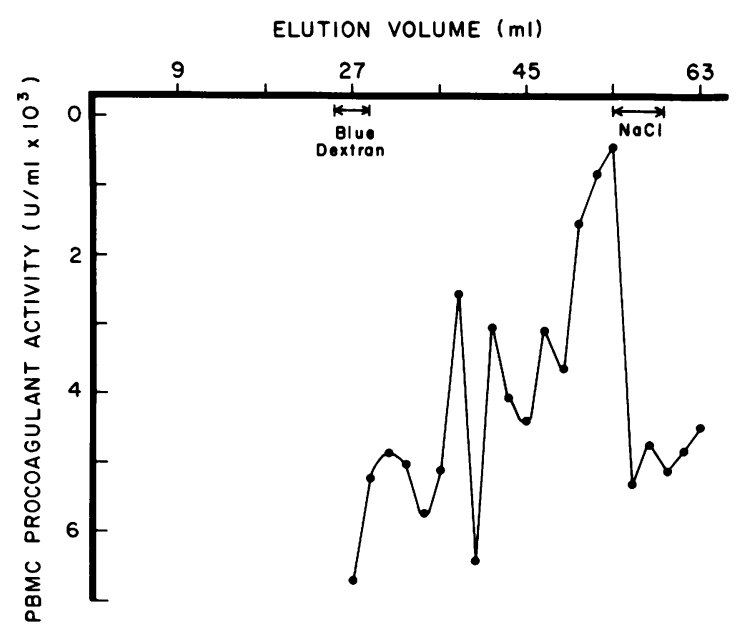

Figure 5. Elution of bovine endothelial cell inhibitor to human PBMC procoagulant activity. Elution fractions from the column (abscissa) were cocultured with PBMCs. The effect on the generation of PCA is shown on the ordinate. Void volume of the column is marked with blue dextran and represents molecules of molecular weight $>1,500$. The inhibitor was detected in the elution fraction just before the elution of $\mathrm{NaCl}$, confirming that the inhibitor is of very low molecular weight.
Table IV. Appearance of BAE Inhibitor of Monocyte $P C A$ and of PA After Refeeding Confluent Cultures with Serum-containing Media

\begin{tabular}{lll}
\hline Time & $\mathrm{PCA}^{*}$ & $\mathrm{PA}^{*}$ \\
\hline & $\%$ inhibition & $U / 2 \times 10^{6}$ cells \\
& 52 & 2 \\
$48 \mathrm{~h}$ & 82 & 3 \\
$72 \mathrm{~h}$ & 73 & 19 \\
\hline
\end{tabular}

* At timed intervals, culture medium was removed and assayed for endothelial cell inhibitor of monocyte PCA. Corresponding cell monolayers were extracted for PA activity.

and assayed for BAE procoagulant inhibitor, and cell monolayers were extracted for PA assay (Table IV). Both BAE procoagulant inhibitor and PA appeared in confluent culture supernatants 24-72 $\mathrm{h}$ after refeeding with serum-containing media. However, PCA inhibitory activity peaked at $48 \mathrm{~h}$, whereas PA activity was $25 \%$ of maximum at $48 \mathrm{~h}$, evidence that these two activities are properties of different molecules. As reported above, BAE procoagulant inhibitor was acid-labile (Table I), whereas PA is acid resistant (21), further indicating that these two substances are different.

Since BAEs actively metabolize arachidonic acid by cyclooxygenase and lipooxygenase pathways (1), we examined the effect of indomethacin on the appearance of the BAE inhibitor of PBMC procoagulant activity (Table $\mathrm{V}$ ). When indomethacin $(10 \mu \mathrm{M})$ was added to BAE cultures at time 0, PBMC had significantly more PCA when cocultured with $\mathrm{Cm}$ (24 and 48 h), compared with PBMC procoagulant activity in the absence of indomethacin $(P<0.025)$. The indomethacin effect on BAE inhibitor was lost when PBMCs were cocultured with $\mathrm{Cm}$ that had been incubated up to 72 and $96 \mathrm{~h}$. Control experiments showed that indomethacin did not alter PBMC generation of PCA or the expression of PCA in our clotting assay. Arachi-

Table V. Inhibition of Monocyte Generation of PCA by Endothelial Cell: Effect of Indomethacin

\begin{tabular}{lll}
\hline & PCA* $^{*}$ & \\
\cline { 2 - 3 } Time & Without indomethacin & With indomethacin \\
\hline $24 \mathrm{~h}$ & $61 \pm 07$ & $81 \pm 08 \S$ \\
$48 \mathrm{~h}$ & $36 \pm 12$ & $62 \pm 16 \S$ \\
$72 \mathrm{~h}$ & $11 \pm 03$ & $23 \pm 07$ \\
$96 \mathrm{~h}$ & $6 \pm 03$ & $1 \pm 01$ \\
\hline
\end{tabular}

* Percent of baseline activity at time 0 . $¥ 10 \mu \mathrm{M}$ indomethacin added to confluent BAE monolayers refed with DMEM + $10 \%$ FBS (time 0 ).

$\S P<0.025$. 
donate-induced platelet aggregation was inhibited by $\mathrm{Cm}$ (0-96 h), demonstrating a biologic presence of indomethacin throughout BAE culture (data not shown). Despite an early suppression of inhibitor, these results do not demonstrate a major role for prostaglandins in this inhibitory effect.

\section{Discussion}

PBMs have been shown to participate in the cellular initiation of coagulation and the generation of fibrin (22). In vitro, monocytes can generate procoagulant material (tissue factor) and thus activate the extrinsic pathway, after stimulation by endotoxin, mitogens, antigens, immune complexes, or activated complement $(23,24)$. Monocyte tissue factor is also felt to play a role in the immune response (25), in that impaired mononuclear cell tissue factor generation has been observed in patients with immunodeficiency (26). In vitro leukocyte PCA has been correlated with clinical delayed hypersensitivity reactions (27). The generation of PCA by monocytes is induced (28) and supported $(19,29)$ by their interaction with $T$ lymphocytes, thus providing a further link to the immune response. On the basis of these studies, there is ample evidence that monocytes play an integral part in the expression of cellular immunity and blood coagulation.

Previous investigations have indicated that vascular endothelial cells have important interactions with components of blood coagulation (1-6). There is also evidence that vascular endothelial cells play a role in the initiation of immune responses. Recent studies have shown that human endothelial cells have antigen-presenting properties (30) and can function as accessory cells for mitogen-induced $\mathrm{T}$ lymphocyte activation (31).

In addition to the growing evidence cited above for interactions between circulating monocytes, lymphocytes, and vascular endothelial cells that are important in the expression of cellular immunity and coagulation, we present evidence that BAEs elaborate an inhibitor of the generation of LPS-stimulated human monocyte PCA. This inhibitor was demonstrated to be potent, temperature stable, acid sensitive, and soluble. It had a molecular weight of $<1,500$ by gel filtration. Indomethacin added to BAE cultures delayed its appearance in culture supernatants but did not abolish this effect. Bovine SMCs did not produce inhibitor. Cell mixing experiments demonstrated that the inhibitor directly decreased monocyte PCA generation and interfered with the $\mathrm{T}$ lymphocyte collaboration required for an amplification of monocyte PCA. Thus, these findings provide further evidence that interactions between circulating monocytes, lymphocytes, and vascular endothelial cells are important in the modulation of coagulation.

\section{Acknowledgments}

We thank Ms. Thea Zimmerman and Randy Viola for technical help, and O. D. Ratnoff, M.D. for reviewing the manuscript.

This work was supported by grants HL01661, HL20924, and HL25922 from the National Heart, Lung and Blood Institute, and by grants from the American Heart Association, the American Lung Association, and their Northeast Ohio Affiliates.

\section{References}

1. Bunting, S., R. Gryglewski, S. Moncada, and J. R. Vane. 1976. Arterial walls generate from prostaglandin endoperoxides a substance (prostaglandin $\mathrm{X}$ ) which relaxes strips of mesenteric and coeliac arteries and inhibits platelet aggregation. Prostaglandins. 12:897-913.

2. Loskutoff, D. J., and T. S. Edgington. 1977. Synthesis of a fibrinolytic activator by endothelial cells. Proc. Natl. Acad. Sci. USA. 74:39033907.

3. Jaffe, E. A., L. W. Hoyer, and R. L. Nachman. 1973. Synthesis of antihemophilic factor antigen by cultured human endothelial cells. J. Clin. Invest. 52:2757-2764.

4. Maynard, J. R., B. E. Dreyer, M. B. Stemerman, and F. A. Pitlick. 1977. Tissue-factor coagulant activity of cultured human endothelial and smooth muscle cells and fibroblasts. Blood. 50:387-396.

5. Lollar, P., J. C. Hoak, and W. G. Owen. 1980. Binding of thrombin to cultured human endothelial cells. J. Biol. Chem. 255:10279-10283.

6. Owen, W. G., and C. T. Esmon. 1981. Functional properties of an endothelial cell cofactor for thrombin-catalyzed activation of protein C. J. Biol. Chem. 256:5532-5535.

7. Gordon, S., J. C. Unkeless, and Z. A. Cohn. 1974. Induction of macrophage plasminogen activator by endotoxin stimulation and phagocytosis. Evidence for a two-stage process. J. Exp. Med. 140:9951010.

8. Goodnough, L. T., and H. Saito. 1982. Specific binding of thrombin by human peripheral blood monocytes: possible role in the clearance of activated clotting factors from the circulation. J. Lab. Clin. Med. 99:873-884.

9. Rickles, F. R., J. A. Hardin, F. A. Pitlick, L. W. Hoyer, and M. E. Conrad. 1973. Tissue factor activity in lymphocyte cultures from normal individuals and patients with hemophilia A. J. Clin. Invest. 52:1427-1434.

10. Ziats, N. P., and A. L. Robertson, Jr. 1981. Effects of peripheral blood monocytes on human vascular cell proliferation. Atherosclerosis. 38:401-410.

11. Hansson, G. K., T. Bjiornheden, and G. Bondjers. 1981. Fcdependent binding of monocytes to areas with endothelial injury in the rabbit aorta. Exp. Mol. Pathol. 34:264-280.

12. Robertson, A. L., Jr. 1980. Arterial endothelium in the initial stages of atherogenesis in atherosclerosis V. Proc. Fifth Int. Symp. Ath erosclerosis. A. M. Gotto, L. C. Smith, and B. Allen, editors. SpringerVerlag New York, Inc., New York. 103-111.

13. Duguid, J. B. 1946. Thrombosis as a factor in the pathogenesis of coronary atherosclerosis. J. Pathol. 58:207-212.

14. Booyse, F. M., B. J. Sedlak, and M. E. Rafelson, Jr. 1975. Culture of arterial endothelial cells. Characterization and growth of bovine aortic cells. Thromb. Diath. Haemorrh. 34:825-839.

15. Schwartz, S. M. 1978. Selection and characterization of bovine aortic endothelial cells. In Vitro (Rockville). 14:966-980.

16. Robertson, Jr., A. L. 1975. Envelope technique for selective isolation of cells from multilayer organ cultures for metabolic studies. Tissue Culture Assoc. Manual. 1:139-140.

17. Loos, H., B. Blok-Schut, R. vanDorn, R. Hoksebergen, A. B. de la Riviere, and L. Meerhof. 1976. A method for the recognition and separation of human blood monocytes on density gradients. Blood. 48:731-742.

18. Kleinhenz, M. E., and L. T. Goodnough. 1982. Stimulation of 
monocyte tissue factor production and suppressor function by the chemotactic peptide F-MET-LEU-PHE (FMLP). Clin. Res. 30:372A. (Abstr.)

19. Levy, G. A., and T. S. Edgington. 1980. Lymphocyte cooperation is required for amplification of macrophage procoagulant activity. $J$. Exp. Med. 151:1232-1244.

20. Goldsmith, G. H., N. P. Ziats, A. L. Robertson, Jr. 1981. Studies on plasminogen activator and other proteases in subcultured human vascular cells. Exp. Mol. Path. 35:257-264.

21. Levin, E. G., and D. J. Loskutoff. 1980. Serum-mediated suppression of cell-associated plasminogen activator activity in cultured endothelial cells. Cell. 22:701-707.

22. Schelley, W. B., and L. Juhlin. 1977. Induction of fibrin thrombi by monocytes. Nature (Lond.). 270:343-344.

23. Rickles, F. R., J. Levin, J. A. Hardin, C. F. Barr, and M. E. Conrad, Jr. 1977. Tissue factor generation by human mononuclear cells: effects of endotoxin and dissociation of tissue factor generation from mitogenic response. J. Lab. Clin. Med. 89:792-803.

24. Schwartz, B. S., and T. S. Edgington. 1981. Immune complexinduced human monocyte procoagulant activity. I. A rapid unidirectional lymphocyte-instructed pathway. J. Exp. Med. 154:892-906.
25. Edwards, R. L., and F. R. Rickles. 1980. The role of monocyte tissue factor in the immune response. Lymphokine Rep. 1:181-210.

26. Ballow, M., and F. R. Rickles. 1980. Impaired mononuclear cell tissue factor generation in patients with immunodeficiency disease. Blood. 56:402-408.

27. Geczy, C. L., and P. A. Meyer. 1982. Leukocyte procoagulant activity in man: an in vitro correlate of delayed type hypersensitivity. J. Immunol. 128:331-336.

28. Levy, G. A., B. S. Schwartz, and T. S. Edgington. 1981. The kinetics and metabolic requirements for direct lymphocyte induction of human procoagulant monokines by bacterial lipopolysaccharide. $J$. Immunol. 127:357-363.

29. Edwards, R. L., and R. F. Rickles. 1980. The role of human T cells (and T cell products) for monocyte tissue factor generation. $J$. Immunol. 125:606.

30. Hirschberg, H., O. J. Berger, and E. Thorsby. 1980. Antigenpresenting properties of human vascular endothelial cells. J. Exp. Med. 152:249s-255s

31. Ashida, E. R., A. R. Johnson, and P. E. Lipsky. 1981. Human endothelial cell-lymphocyte interaction. J. Clin. Invest. 67:1490-1499. 